\title{
COMPARAÇÃO DO DESEMPENHO DA LIPASE DE Candida rugosa IMOBILIZADA EM SUPORTE HÍBRIDO DE POLISSILOXANO-POLIVINILÁLCOOL EMPREGANDO DIFERENTES METODOLOGIAS
}

\author{
Ariela V. Paula, Ana B. R. Moreira, Luciana P. Braga e Heizir F. de Castro* \\ Escola de Engenharia de Lorena, Universidade de São Paulo, CP 116, 12602-810 Lorena - SP, Brasil \\ Laura M. Bruno \\ Embrapa Agroindústria Tropical, Rua Dr ${ }^{\mathrm{a}}$. Sara Mesquita, 2270, 60511-110 Fortaleza - CE, Brasil
}

Recebido em 16/10/06; aceito em 25/5/07; publicado na web em 9/11/07

\begin{abstract}
COMPARATIVE PERFORMANCE OF Candida rugosa LIPASE IMMOBILIZED ON POLYSILOXANE POLYVINYL ALCOHOL HYBRID SUPPORT USING DIFFERENT METHODOLOGIES. The efficiency for immobilizing microbial Candida rugosa lipase on a hybrid matrix of polysiloxane polyvinyl alcohol, by adsorption, covalent coupling and encapsulation was compared. The activities of immobilized derivatives were evaluated using $p$-nitrophenylpalmitate (hydrolysis) and butyric acid and butanol (esterification) as substrates. Operational stability and storage tests were also performed. Among the procedures tested, the proposed matrix was efficient for immobilizing $C$. rugosa lipase by adsorption and covalent coupling techniques and unsuitable for encapsulation purposes. The results reveal that better catalytic properties in both aqueous and organic media were demonstrated by the covalent coupling POSPVA immobilized lipase, including also satisfactory half-life and good storage stability.
\end{abstract}

Keywords: lipase; hybrid support; adsorption.

\section{INTRODUÇÃO}

Enzimas na sua forma nativa (enzimas livres) têm sido usadas por séculos na indústria de alimentos e mais recentemente nas indústrias farmacêuticas e químicas ${ }^{1}$. Sua estrutura e modo de ação vêm sendo gradativamente elucidados por métodos experimentais bem estabelecidos, como técnicas clássicas de Raio-X e avançadas de Ressonância Nuclear Magnética (RNM). Modernas metodologias de engenharia genética têm possibilitado a produção de enzimas em larga escala ou a modificação de sua estrutura primária, alterando, portanto, algumas de suas características físico-químicas e biológicas ${ }^{2}$. De igual significância são as recentes técnicas de evolução direcionada, as quais têm permitido, via modificação do DNA, a preparação de enzimas especialmente dirigidas para uma determinada finalidade, isto é, enzimas que atuam em valores extremos de $\mathrm{pH}$ e temperatura, bem como em presença de meios não convencionais (solventes orgânicos, fase gasosa e $\mathrm{CO}_{2}$ supercrítico) ${ }^{3}$.

$\mathrm{O}$ valor de venda de enzimas para uso em indústrias de alimentos, detergentes, especialidades químicas perfizeram um total de aproximadamente US\$ 700 milhões em 1992 e aumentaram para US\$ 2 bilhões em $2004^{4}$. De acordo com as projeções, o crescimento no mercado de enzimas é de aproximadamente $4-5 \%$ ao ano, acompanhada pela redução de preço, devido ao grande número de empresas que vêm comercializando enzimas com preços mais competitivos. Como resultado, o mercado previsto para 2009 é da ordem de 2,4 bilhões ${ }^{4}$.

De interesse particular é o aumento do uso de enzimas imobilizadas, termo empregado por Katchalski-Katzir ${ }^{5}$ na primeira Conferência de Engenharia Enzimática realizada em Henniker, NH, EUA em 1971, para designar enzima fisicamente confinada ou localizada numa certa região do espaço, com retenção de sua atividade catalítica, podendo ser usada repetida e continuamente ${ }^{6}$. Nesta técnica, a enzima fica retida no interior (poros) ou na superfície de um material que é utilizado como suporte. O complexo enzima-

*e-mail: heizir@dequi.eel.usp.br suporte mantém as características físicas do suporte e, ao mesmo tempo, retém a atividade biológica da enzima na forma solúvel. O termo enzima imobilizada inclui: a modificação das enzimas de forma a torná-las insolúveis em água; a utilização de enzimas na forma solúvel em reatores equipados com membranas de ultrafiltração, que permitem o escoamento dos produtos da reação, porém retendo a enzima no interior do reator e, a restrição da mobilidade da enzima pela ligação à outra molécula, que torna o sistema insolúvel no meio reacional ${ }^{6}$.

O sistema imobilizado permite a condução de reações em reatores contínuos, com fácil separação de catalisador-produto, e aumento da produtividade do processo (massa de produto formado/ unidade de tempo).

A tecnologia de imobilização de enzimas envolve basicamente a escolha de um suporte e do método de imobilização nesse suporte, que resulte num preparado imobilizado ativo e estável ${ }^{7}$. Dispõese atualmente de várias técnicas de imobilização de enzimas, assim como de um grande número de matrizes, englobando materiais orgânicos e inorgânicos, naturais ou sintéticos ${ }^{6,7}$.

Apesar da existência de suportes baratos, como polímeros e minerais naturais, a utilização de enzimas imobilizadas em processos tem exigido a elaboração de matrizes específicas para essa finalidade, que resultem em preparados imobilizados com elevadas atividades e características hidrodinâmicas adequadas ao uso em reatores ${ }^{8}$.

As mais recentes tecnologias requerem materiais com combinação de propriedades que não são encontradas nos materiais convencionais. Materiais híbridos orgânico-inorgânico são preparados pela combinação de componentes orgânicos e inorgânicos e constituem uma alternativa para a produção de novos materiais multifuncionais, com uma larga faixa de aplicações ${ }^{9}$.

Independentemente da estratégia utilizada para preparar uma matriz híbrida, o processo sol-gel é, indiscutivelmente, o mais empregado $^{9}$. O processo sol-gel envolve diversas variáveis, como tempo e temperatura da reação, natureza do catalisador, concentração de reagentes, entre outros ${ }^{10}$. Estas variáveis determinam as caracterís- 
ticas finais dos materiais, incluindo a porcentagem de hidrólise e condensação de grupos reativos, densidade de reticulação e homogeneidade do produto. Além disso, aditivos químicos podem ser usados para melhorar o processo e obter materiais com melhores propriedades, o que possibilita modificações nas propriedades mecânicas, controle de porosidade e ajuste no balanço hidrofílico/ hidrofóbico ${ }^{9,10}$.

Materiais sol-gel têm sido empregados como suporte para a imobilização de enzimas tanto por encapsulação ${ }^{11,12}$, como por ligação covalente ${ }^{13,14}$.

A reação química envolvida num processo sol-gel convencional, baseado em derivados alcóxidos, é mostrada abaixo. A etapa (1) corresponde à hidrólise, enquanto a (2) corresponde à policondensação do silano.

$$
\mathrm{Si}(\mathrm{OEt})_{4} \underset{(1)}{\longrightarrow} \mathrm{n}(\mathrm{EtO})_{\mathrm{x}} \mathrm{Si}(\mathrm{OH})_{\mathrm{y}-\mathrm{x}} \underset{(2)}{\longrightarrow}\left(\mathrm{SiO}_{2}\right)_{\mathrm{n}}
$$

Recentemente foi testada com sucesso uma matriz híbrida constituída de polissiloxano-álcool polivinílico (POS-PVA) para imobilização de diferentes fontes de lipase: Mucor miehei ${ }^{14,15}$, pancreática $^{16,17}$ e Candida antarctica ${ }^{18}$. Essa matriz combina os atributos físico-químicos de materiais inorgânicos e orgânicos, permitindo a manipulação da hidrofilicidade e hidrofobicidade, condutividade elétrica, carga iônica, porosidade e propriedades mecânicas em geral $^{10,14}$, bem como elevada atividade e estabilidade.

Este trabalho complementa os estudos anteriormente desenvolvidos $^{14-18}$ dando ênfase na utilização dessa matriz para imobilização da lipase de Candida rugosa. O objetivo foi comparar a eficiência de diferentes métodos de imobilização (Adsorção Física, Ligação Covalente e Encapsulação) na obtenção de sistemas imobilizados ativos e estáveis para subseqüente aplicação na síntese e hidrólise de ésteres.

\section{PARTE EXPERIMENTAL}

\section{Materiais}

A lipase microbiana (Candida rugosa, tipo VII) foi adquirida da Sigma-Aldrich Chemical Co. (St. Louis, MO, EUA), com atividade específica de hidrólise do $p$-nitrofenil palmitato igual 1868 $\mathrm{U} / \mathrm{mg}$. Os outros reagentes empregados foram: tetraetil ortossilicato (TEOS), adquirido da Sigma-Aldrich Chemical; polietilenoglicol (PEG 1500 marca Synth, adquirido da Hipperquímica, Santo André/ SP, Brasil); $n$-Butanol (99\%) e ácido butírico, ambos adquiridos da Merck KGaA (Darmstadt, Alemanha); $n$-Heptano (Reagen Chemical Co, São Paulo, Brasil); peneira molecular (4 Å), adquirida da Sigma-Aldrich Chemical, goma arábica em pó, pura (Synth). Todos os outros reagentes empregados foram de grau analítico.

\section{Síntese do suporte}

O composto híbrido de POS-PVA foi sintetizado, conforme metodologia descrita por Bruno et al ${ }^{15}$, de acordo com as etapas a seguir descritas:

I. Uma mistura de $50 \mathrm{~mL}$ de tetraetil ortossilicato (TEOS), 50 $\mathrm{mL}$ de etanol, $60 \mathrm{~mL}$ de uma solução aquosa de álcool polivinílico a $2 \%(\mathrm{~m} / \mathrm{v})$ e trinta gotas de $\mathrm{HCl}$ concentrado, foi aquecida a $60{ }^{\circ} \mathrm{C}$, sob agitação, durante $40 \mathrm{~min}$.

II. O suporte preparado na presença de lipase (encapsulação) e ausência de lipase (suporte puro) foi transferido para um molde de silicone $(21,5 \times 21,5 \mathrm{~cm})$ e levado à secagem a temperatura ambiente até completa solidificação do material sol-gel.
III. Após secagem, o composto foi triturado até que o material passasse completamente por uma peneira padrão série Tyler de 80 mesh e ficasse retido em peneira de 100 mesh. O suporte puro (formação da rede interpenetrada de polissiloxano e álcool polivinílico - POS-PVA) foi utilizado para imobilização da lipase pelas técnicas de adsorção física e ligação covalente.

\section{Tratamento do suporte}

Dependendo da técnica de imobilização empregada, foi necessário efetuar tratamentos do suporte de forma a adequar seu uso para imobilização da enzima lipase. Para técnica de imobilização por adsorção, o suporte foi previamente neutralizado com solução aquosa de $\mathrm{NaOH}(0,1 \mathrm{M})$, conforme metodologia descrita por Gomes et al. ${ }^{19}$. Na técnica de imobilização por ligação covalente o suporte foi ativado com uma solução de glutaraldeído 2,5\% (v/v), utilizando a proporção de $10 \mathrm{~mL}$ da solução para cada $1 \mathrm{~g}$ de suporte $^{16}$. Após os tratamentos, o suporte foi lavado exaustivamente com água destilada e solução tampão de fosfato de sódio $(0,1 \mathrm{M}$, $\mathrm{pH} 8,0)$, sendo levado à secagem em estufa $\left(60^{\circ} \mathrm{C}\right)$ por $24 \mathrm{~h}$.

\section{Imobilização da lipase de Candida rugosa em POS-PVA}

A imobilização da lipase no suporte puro (por adsorção) ou ativado (ligação covalente) consistiu do contato da solução enzimática com o suporte (500 unidades de atividade/g suporte) juntamente com solução aquosa de polietilenoglicol (MW 1500), por um período de $24 \mathrm{~h}$ a $4^{\circ} \mathrm{C}$. A lipase imobilizada foi recuperada por filtração a vácuo e o sistema imobilizado lavado com hexano. No procedimento de encapsulação da lipase, após obtenção do gel, a temperatura foi reduzida de 60 para $30^{\circ} \mathrm{C}$. Foram adicionados 0,5 $\mathrm{g}$ de lipase livre tomando por base o fato de que são produzidos $2 \mathrm{~g}$ de suporte POS-PVA por batelada de reagentes. O material sol-gel foi levado à secagem a temperatura ambiente. Em todas as preparações de lipase imobilizada foram quantificados os teores de umidade e atividade enzimática. O rendimento de imobilização $(\eta \%)$ foi calculado pela Equação 1:

$\eta(\%)=\frac{U_{S}}{U_{0}} \times 100$

em que: $U_{0}=$ unidades de atividade oferecidas para imobilização; $U_{S}=$ unidades de atividade enzimática total presente no suporte (atividade $\mathrm{x}$ massa seca).

\section{Atividade hidrolítica}

A atividade hidrolítica da enzima livre e imobilizada foi determinada usando $p$-nitrofenilpalmitato $(p$-NPP, massa molecular $=$ $377,5 \mathrm{~g} / \mathrm{Mol}$ ) como substrato, de acordo com metodologia descrita por Pencreac'h e Baratti ${ }^{20}$. O substrato foi incubado em uma cubeta no espectrofotômetro (Varian, Modelo Cary 50) com circulação de água na temperatura de $37^{\circ} \mathrm{C}$. Após o equilíbrio da temperatura, $0,3 \mathrm{~mL}$ de solução enzimática $(0,4 \mathrm{mg} / \mathrm{mL})$ ou cerca de $5-10 \mathrm{mg}$ de lipase imobilizada foram adicionados ao sistema. As absorbâncias foram medidas a $410 \mathrm{~nm}$, contra um branco contendo $0,3 \mathrm{~mL}$ de tampão fosfato de sódio $(50 \mathrm{mM}, \mathrm{pH} 8,0)$ em substituição à enzima, em intervalos de $15 \mathrm{~s}$, ao longo de $5 \mathrm{~min}$ de reação. O coeficiente de absorção molar do $p$-NPP $\left(1,32 \times 10^{-4} \mathrm{M}^{-1} \mathrm{~cm}^{-1}\right)$ foi usado para calcular a atividade enzimática. Uma unidade de atividade enzimática foi definida como a quantidade de enzima capaz de catalisar a produção de $1 \mu \mathrm{mol}$ de $p$-nitrofenol por minuto nas condições experimentais estabelecidas. $\mathrm{O}$ valor de absorbância no tem- 
po de 1 min foi determinado por regressão linear das leituras de absorbâncias obtidas. As atividades foram expressas em U/mg.

Adotando esse procedimento de análise, foram ainda determinados: influência do $\mathrm{pH}(6,0-8,5)$, temperatura $\left(40-60^{\circ} \mathrm{C}\right)$ e concentração do substrato $(100-1000 \mu \mathrm{M})$ nas atividades da lipase nas formas livre e imobilizada. As constantes cinéticas $K_{m} \mathrm{e} V_{\max }$ foram determinadas pelo Programa Enzyme fitter (Leatherbarrow, R. J., 1987, Elsevier, Biosoft, Amsterdam, The Netherlands).

\section{Atividade de esterificação}

A atividade de esterificação foi determinada pela formação do butirato de butila na reação de $n$-butanol $(0,10 \mathrm{M})$ com ácido butírico $(0,10 \mathrm{M})$ em heptano, empregando $0,5 \mathrm{~g}$ de lipase imobilizada, a $37^{\circ} \mathrm{C}$, por um período máximo de $24 \mathrm{~h}$. A reação foi iniciada pela adição do biocatalisador ao meio reacional $(20 \mathrm{~mL})$ em frascos cilíndricos fechados de $100 \mathrm{~mL}$ (altura de $8,5 \mathrm{~cm}$ e diâmetro de 2,7 $\mathrm{cm})$ sob agitação de $150 \mathrm{rpm}$. Alíquotas foram retiradas do meio reacional em intervalos de $4 \mathrm{~h}$ para quantificação das substâncias presentes. Uma unidade de atividade de esterificação foi definida como a quantidade de enzima que conduz à formação de $1 \mu \mathrm{mol}$ de butirato de butila por minuto nas condições do ensaio.

\section{Testes de estabilidade}

Para os testes de estabilidade de estocagem, uma amostra da lipase imobilizada foi acondicionada em um frasco e estocada a 4 ${ }^{\circ} \mathrm{C}$ por um período máximo de 60 dias. Alíquotas de $0,1 \mathrm{~g}$ da lipase imobilizada foram retiradas mensalmente para determinação das atividades hidrolíticas residuais empregando o método colorimétrico, conforme metodologia descrita anteriormente.

A estabilidade operacional dos sistemas imobilizados foi verificada na síntese do butirato de butila em regime de bateladas consecutivas com reutilização dos sistemas imobilizados. As reações foram realizadas utilizando-se $0,5 \mathrm{~g}$ dos sistemas imobilizados (massa seca) e $20 \mathrm{~mL}$ de substrato contendo $0,10 \mathrm{M}$ de ácido butírico e $0,10 \mathrm{M}$ de $n$-butanol em heptano, por um período máximo de $24 \mathrm{~h}$ a $37{ }^{\circ} \mathrm{C}$, sob agitação $(150 \mathrm{rpm})$ e monitoradas no tempo inicial e final. Entre as bateladas, a lipase imobilizada foi lavada com uma mistura hexano/acetona (1:1) para remoção dos reagentes e/ou produtos eventualmente retidos no suporte. Após filtração a vácuo, a lipase imobilizada foi reutilizada. A atividade de esterificação foi calculada ao final de cada ciclo (24 h), tomando por base a concentração de butirato de butila formado, por grama de biocatalisador, por minuto de reação.

\section{Métodos analíticos}

A concentração de ácido butírico foi determinada por titulação, empregando-se solução de $\mathrm{KOH}$ 0,02 M e fenoftaleína como indicador. As concentrações de $n$-butanol e butirato de butila foram determinadas por cromatografia gasosa (Cromatógrafo Varian, Modelo CG 3800, Varian, Inc. Corporate Headquarters, Palo Alto, CA, EUA), utilizando uma coluna empacotada (6ft S\# DEGS WHP 80/100 mesh, $\mathrm{HP})$ e as seguintes condições: nitrogênio como gás de arraste $(30 \mathrm{~mL} /$ min); volume de injeção de $1 \mu \mathrm{L}$; detector de ionização de chama; temperatura da coluna $65^{\circ} \mathrm{C}$; hexanol como padrão interno.

\section{Análise por espectroscopia na região do infravermelho por transformada de Fourier}

As amostras de POS-PVA puro e ativado com glutaraldeído, lipase livre e imobilizada por adsorção e por ligação covalente fo- ram submetidas à análise na região do infravermelho (Espectrofotômetro de infravermelho, Spectrum One - Perkin Elmer), com geração de dados pelo programa Spectrum versão 3.02. Os espectros foram obtidos na faixa de comprimento de onda de 4000 a 400 $\mathrm{cm}^{-1}$, utilizando a técnica de análise de superfície. As análises foram efetuadas com o material colocado somente na superfície do porta-amostra.

\section{RESULTADOS E DISCUSSÃO}

\section{Imobilização da lipase de Candida rugosa em POS-PVA empregando diferentes metodologias}

Lipase de Candida rugosa foi imobilizada por adsorção física (ADS), ligação covalente (LC) e encapsulação (EC) em POS-PVA e o poder catalítico dos sistemas imobilizados foi comparado em termos de atividade hidrolítica e recuperação de atividade no suporte. Empregando POS-PVA puro (imobilização por adsorção física), foram obtidas amostras de lipase imobilizada com atividade média de $480 \mathrm{U} / \mathrm{mg}$, o que correspondeu a 96,5\% de rendimento de imobilização. No caso da lipase imobilizada em POS-PVA ativado com glutaraldeído (LC), foi verificado um pequeno decréscimo na atividade e no rendimento quando comparado aos mesmos parâmetros referentes à imobilização por ADS. A atividade média da imobilização por LC foi da ordem de $407 \mathrm{U} / \mathrm{mg}$, correspondendo a $81,5 \%$ de rendimento de imobilização. Em ambos procedimentos foram obtidos sistemas imobilizados com baixo teor de umidade $(<5 \%)$.

A menor expressão de atividade catalítica verificada para a lipase imobilizada por LC pode ter sido ocasionada por uma modificação conformacional da enzima durante a etapa de fixação ao suporte ativado com glutaraldeído. Isto pode ter alterado a estrutura tridimensional do sítio ativo da enzima, tornando certas partes da molécula enzimática inacessíveis ao substrato $p$-nitro-fenilpalmitato.

Por outro lado, quando foi empregada a técnica de encapsulação, não houve expressão de atividade do sistema resultante. Este resultado pode estar associado à rigidez da estrutura da matriz conferida pelo PVA, que promoveu limitações relacionadas à transferência de massa e impedimento estérico da enzima. Além disso, o sistema imobilizado apresentou aspecto quebradiço sendo considerado totalmente inadequado para o uso proposto, uma vez que um dos fatores que contribuem para a eficiência do processo de encapsulação é a natureza porosa da membrana utilizada para o confinamento da enzima ${ }^{11}$.

No entanto, modificações nas propriedades de materiais híbridos podem ser conseguidas pela variação das combinações dos componentes durante a preparação do suporte ${ }^{9,11}$. Assim, com o intuito de tornar o suporte mais poroso e menos reticulado, algumas estratégias, entre as quais redução da concentração de PVA e substituição deste polímero por outras macromoléculas (ciclodextrina e polietilenoglicol), foram avaliadas. A redução da concentração do PVA de 2 para $1 \%$ não produziu o efeito desejado e apesar dos sistemas encapsulados preparados com ciclodextrina ou polietilenoglicol terem apresentado um aspecto pastoso e úmido (umidade $>30 \%$ ), suas atividades hidrolíticas foram muito inferiores (dados não mostrados) daquelas obtidas pelos sistemas imobilizados por adsorção e ligação covalente.

Desta forma, neste trabalho para efeito de comparação do desempenho da matriz híbrida POS-PVA para imobilização da lipase foram considerados apenas os sistemas imobilizados obtidos pelas técnicas de adsorção física e de ligação covalente. 
Propriedades bioquímicas e cinéticas da lipase livre e imobilizada em POS-PVA

A determinação do $\mathrm{pH}$ ótimo das lipases livre e imobilizada em POS-PVA foi realizada pela variação do valor do $\mathrm{pH}$ do substrato numa faixa de 5,5 a 8,5 , a $37{ }^{\circ} \mathrm{C}$ (Figura 1). Verifica-se que o $\mathrm{pH}$ ótimo de 7,5 para a enzima livre foi mantido para a lipase imobilizada obtida por adsorção física. No entanto, quando se empregou o método de imobilização por ligação covalente houve um deslocamento do valor do $\mathrm{pH}$ ótimo para 8,0. Observa-se também que a enzima imobilizada por ligação covalente apresentou atividade relativa superior à atividade da lipase livre e da lipase imobilizada por adsorção física na faixa de $\mathrm{pH}$ abaixo de 7,0 e acima de 8,0, sugerindo que a imobilização por ligação covalente também ofereceu uma certa proteção à enzima, quando o meio reacional apresentou $\mathrm{pH}$ diferente do ótimo. Alterações no $\mathrm{pH}$ ótimo de lipases após a imobilização também foram verificadas por outros pesquisadores. Chiou e $\mathrm{Wu}^{8}$ relataram uma mudança do $\mathrm{pH}$ ótimo de 8,0 para 9,0 após imobilização da lipase de C. rugosa em quitosana, empregando ligação covalente. Fadiloglu e Soylemez ${ }^{21}$ observaram uma redução do pH ótimo de 7,0 para 6,5 após a imobilização da lipase de $C$. rugosa em Celite, enquanto que Perez et al. ${ }^{22}$ verificaram um aumento do $\mathrm{pH}$ ótimo de 7,0 para 8,5 após a imobilização da mesma lipase em celulignina ativada com metaperiodato de sódio.

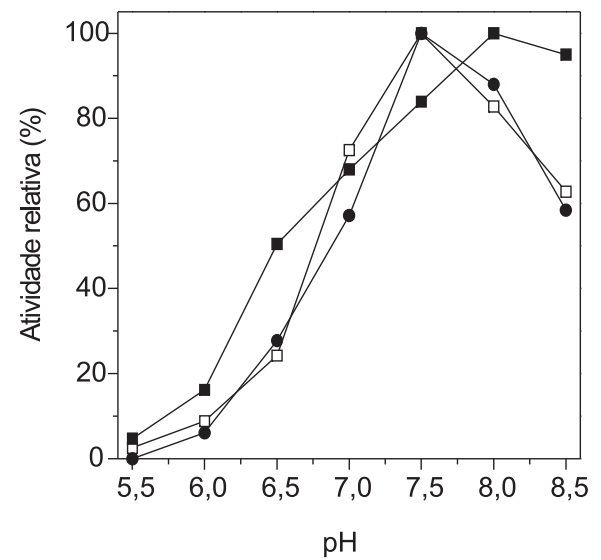

Figura 1. Influência do pH na atividade hidrolítica da lipase livre ( $\square$ ), imobilizada em POS-PVA por adsorção física $(\bullet)$ e por ligação covalente (ם). Ensaio realizado a $37^{\circ} \mathrm{C}$

A influência da temperatura na atividade enzimática foi investigada em tampão fosfato $50 \mathrm{mM}, \mathrm{pH}$ 8,0 numa faixa de temperatura de 37 a $60{ }^{\circ} \mathrm{C}$ (Figura 2). A temperatura ótima dos sistemas imobilizados obtidos por adsorção física $\left(40^{\circ} \mathrm{C}\right)$ e por ligação covalente $\left(55^{\circ} \mathrm{C}\right)$ sofreu uma elevação quando comparada à temperatura ótima da lipase livre $\left(37^{\circ} \mathrm{C}\right)$. Além disso, os dois métodos de imobilização pareceram conferir alguma proteção à enzima, pois a partir de $45{ }^{\circ} \mathrm{C}$ as lipases imobilizadas apresentaram atividades relativas praticamente iguais ou superiores às da lipase livre. Mudanças na temperatura ótima após a imobilização são relatadas por diversos autores ${ }^{19,21,23}$. Entretanto, cada sistema de enzima imobilizada apresenta características únicas dependentes de fatores como fonte de enzima, tipo de suporte, método de imobilização e interação da enzima-suporte.

$\mathrm{O}$ efeito da concentração do substrato sobre a atividade das lipases imobilizadas foi investigado e comparado com o da lipase livre, sob as mesmas condições de reação, empregando soluções

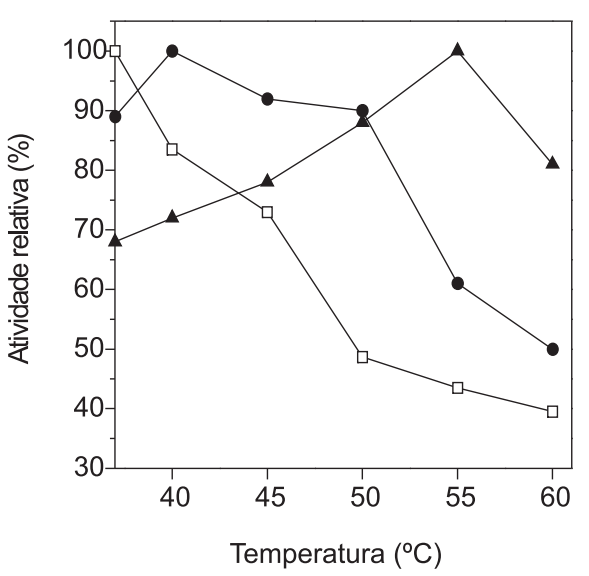

Figura 2. Influência da temperatura na atividade hidrolítica da lipase livre $(\square)$, imobilizada em POS-PVA por adsorção fisica $(\mathbf{O})$ e por ligação covalente (A). Ensaio realizado a $\mathrm{pH} 8,0$

de $p$-NPP de concentrações variando entre 100 a $1000 \mu \mathrm{M}$. Os experimentos foram realizados em $\mathrm{pH} 8,0$ a $37{ }^{\circ} \mathrm{C}$ e os perfis das curvas de velocidade de reação das preparações de lipase livre e imobilizada em função da concentração de $p$-NPP são apresentados na Figura 3. Verifica-se que o aumento na concentração do substrato ( $p$-NPP) de 100 para $400 \mu \mathrm{M}$ resultou em um incremento significativo nas velocidades de reação de todas as preparações de lipase ensaiadas. Para concentrações de substrato superiores a 750 $\mu \mathrm{M}$, a atividade enzimática da lipase tornou-se essencialmente independente da concentração do substrato, seguindo uma cinética do tipo Michaelis-Menten.

Os valores de $K_{m}$ e $V_{\text {max }}$ aparentes foram calculados com o auxílio do programa "Enzyme Fitter", sendo obtidos os valores de $V_{\text {}}$ iguais a $1929 \mu \mathrm{mol} / \mathrm{mg} \min$ (enzima livre); $635 \mu \mathrm{mol} / \mathrm{mg} \min ($ ADS) e $551 \mu \mathrm{mol} / \mathrm{mg} \min$ (LC). Os valores de $K_{m}$ encontrados foram 170 $\mu \mathrm{M}$ (enzima livre); $409 \mu \mathrm{M}$ (ADS) e $210 \mu \mathrm{M}$ (LC), indicando uma mudança da afinidade da lipase pelo substrato, na forma imobilizada. Esta alteração de afinidade foi menor quando a lipase foi imobilizada por ligação covalente.

Com relação á influência do tempo de estocagem sobre a ativi-

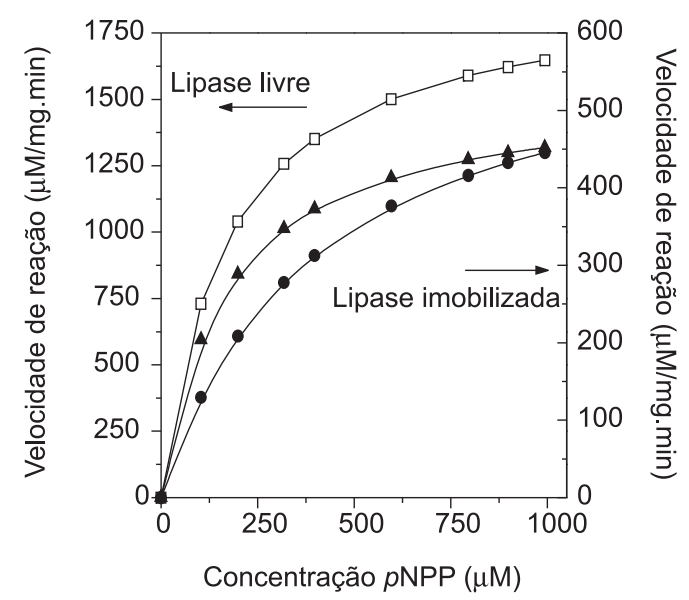

Figura 3. Influência da concentração substrato na velocidade de reação da lipase de Candida rugosa $\left(\mathrm{pH} 8.0\right.$ a $\left.37^{\circ} \mathrm{C}\right)$. As velocidades de reação plotadas no eixo esquerdo são referentes à lipase livre $(\square)$ e as do eixo direito referentes à da lipase imobilizada em POS-PVA por adsorção física (-) e por ligação covalente $(\mathbf{A})$ 
dade das lipases imobilizadas, os resultados revelaram que a lipase imobilizada em POS-PVA por adsorção física apresentou baixa estabilidade, com redução de $44 \%$ da atividade original após 30 dias de armazenamento e $70 \%$ após 60 dias. Por outro lado, a lipase imobilizada por ligação covalente teve sua atividade reduzida em apenas $10 \%$ num período de 30 dias e $23 \%$ após 60 dias de armazenamento. Segundo Zanin e Morais ${ }^{6}$, a estabilidade à estocagem das enzimas imobilizadas em solução ou secas, geralmente é superior àquela da enzima livre, porém isto depende do método de imobilização, do suporte e da solução em que está estocada. Além disso, as enzimas imobilizadas em suportes inorgânicos por meio de ligação covalente são mais estáveis que as imobilizadas em suporte orgânico ${ }^{6}$.

\section{Aplicação dos sistemas imobilizados na síntese de butirato de butila}

Para avaliar a potencialidade das lipases imobilizadas em meio orgânico, foi utilizado como modelo reacional um sistema constituído de $n$-butanol, ácido butírico e solvente (heptano). A cinética de conversão dos materiais de partida em butirato de butila é aprentada na Figura 4. Para lipase imobilizada por ADS a velocidade de reação foi de $72,60 \mu \mathrm{M} / \mathrm{g}$ min, com concentração máxima de butirato de butila de 52,28 mM, após 24 h de reação, enquanto que para a lipase imobilizada por LC, a velocidade de reação foi significativamente maior $(228,10 \mu \mathrm{M} / \mathrm{g} \min )$, atingindo uma concentração similar de butirato de butila $(54,75 \mathrm{mM})$ em apenas $8 \mathrm{~h}$.

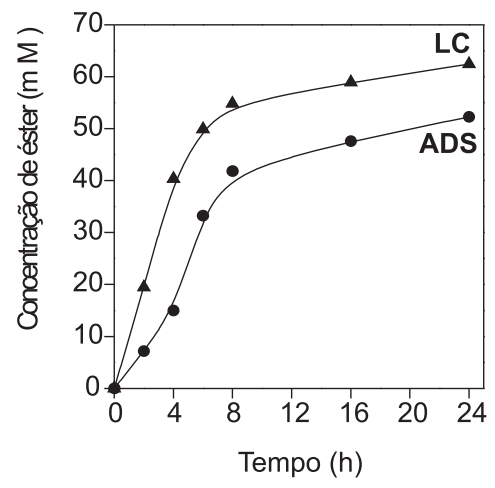

Figura 4. Progresso da esterificação do n-butanol com ácido butírico, empregando lipase imobilizada em POS-PVA por adsorção física (-) e por ligação covalente (A), a $37^{\circ} \mathrm{C}$

Completando esta análise, o perfil de estabilidade operacional das lipases imobilizadas foi estimado por meio de testes de esterificação em regime de bateladas consecutivas. Os resultados

Tabela 1. Estabilidade operacional da lipase imobilizada em POSPVA por adsorção física (ADS) e por ligação covalente (LC) na reação de esterificação do $n$-butanol com ácido butírico em regime de bateladas consecutivas $\left(24 \mathrm{~h} / 37^{\circ} \mathrm{C}\right)$

\begin{tabular}{lcc}
\hline Ciclos & \multicolumn{2}{c}{ Atividade de esterificação $(\mu \mathrm{M} / \mathrm{g}$ min $)$} \\
\hline & ADS & LC \\
1 & 72,60 & 228,10 \\
2 & 40,90 & 217,54 \\
3 & 0,50 & 194,10 \\
4 & - & 118,32 \\
5 & - & 66,95 \\
6 & - & 55,63 \\
\hline
\end{tabular}

são apresentados na Tabela 1. Para o sistema obtido por ADS, observou-se uma perda acentuada da atividade de esterificação na segunda batelada, com subsequiente perda total na terceira batelada, o que correspondeu a um tempo de meia-vida de $39 \mathrm{~h}$. Também houve perda de atividade de esterificação para o sistema obtido por LC. No entanto, essa perda foi menos significativa quanto comparada ao sistema ADS, sendo possível utilizar o sistema LC por seis bateladas consecutivas. O tempo de meia-vida desse derivado imobilizado foi o dobro (81 h) do obtido pela amostra preparada por ADS.

Na Tabela 2 encontra-se um resumo das propriedades catalíticas da lipase de Candida rugosa livre e imobilizada em POS-PVA por adsorção e por ligação covalente.

Tabela 2. Sumário das propriedades catalíticas da lipase de Candida rugosa livre e imobilizada em POS-PVA por adsorção física (ADS) e por ligação covalente (LC)

\begin{tabular}{llll}
\hline Características & $\begin{array}{l}\text { LCR } \\
\text { livre }\end{array}$ & $\begin{array}{l}\text { LCR -POS- } \\
\text { PVA ADS }\end{array}$ & $\begin{array}{l}\text { LCR -POS- } \\
\text { PVA LC }\end{array}$ \\
\hline pH ótimo & 7,5 & 7,5 & 8,0 \\
Temperatura ótima $\left({ }^{\circ} \mathrm{C}\right)$ & 37 & 40 & 55 \\
$K_{m}(\mu \mathrm{M})$ & 170 & 409 & 210 \\
$V_{\max }(\mathrm{U} / \mathrm{mg})$ & 1929 & 635 & 551 \\
$\begin{array}{l}\text { Estabilidade de } \\
\text { estocagem }\left(\mathrm{t}_{1 / 2}, \text { dias }\right)\end{array}$ & $\mathrm{Na}$ & 35 & 161 \\
$\begin{array}{l}\text { Estabilidade } \\
\text { operacional }\left(\mathrm{t}_{1 / 2}, \mathrm{~h}\right)\end{array}$ & $\mathrm{Na}$ & 39 & 81 \\
\hline
\end{tabular}

$\mathrm{Na}$ : não se aplica

\section{Análise por espectroscopia no IV por transformada de Fourier (FTIR)}

As Figuras $5 \mathrm{a}$ e $5 \mathrm{~b}$ mostram os espectros no infravermelho obti-

a)

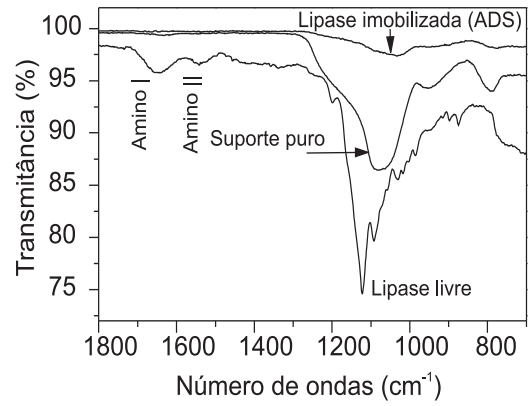

b)



Figura 5. Espectros no infravermelho (a) do suporte puro, lipase livre e imobilizada por adsorção física (ADS) e (b) suporte ativado com glutaraldeído, lipase livre e imobilizada por ligação covalente (LC) 
dos para o suporte puro, suporte ativado, lipase livre e sistemas imobilizados obtidos pelas técnicas de adsorção física e ligação covalente. Para o suporte, o espectro mostra pequenas bandas principalmente entre 1000-1100, correspondendo à ligação Si-O- ${ }^{24}$. A lipase livre apresenta um espectro típico de proteínas com bandas de absorção associadas ao grupo amino (CONH) característico. Na faixa de comprimento de onda situada entre $1600-1700 \mathrm{~cm}^{-1}$ estão exibidos os grupamentos amino primários e secundários ${ }^{25}$. Em ambas lipases imobilizadas os picos característicos diminuíram, possivelmente devido à fixação de lipase livre no suporte sólido. Nenhuma banda adicional foi observada no espectro do sistema imobilizado por ligação covalente, sugerindo que a ligação entre enzima e suporte é da mesma natureza que bandas típicas de proteínas. Além disso, é possível observar uma banda intensa entre 1100 e $1200 \mathrm{~cm}^{-1}$. Comparando-se a intensidade desta banda em ambas lipases imobilizadas, observa-se menor redução quando o método de ligação covalente foi o empregado. Isto provavelmente ocorre porque o glutaraldeído é capaz de reagir com os grupos $\mathrm{OH}$ da superfície do suporte e com os grupos amina da enzima ${ }^{26}$, resultando em bandas semelhantes às da proteína livre.

\section{CONCLUSÕES}

Lipase de Candida rugosa foi imobilizada em suporte híbrido POS-PVA empregando diferentes métodos de imobilização: adsorção física, ligação covalente e encapsulação. As lipases imobilizadas pelas técnicas de adsorção e de ligação covalente apresentaram um rendimento de 96,50 e $81,05 \%$, respectivamente. No entanto, não foi possível recuperar a atividade da lipase de C. rugosa imobilizada em POS-PVA por encapsulação. Após a imobilização foi observada alteração nos parâmetros de $\mathrm{pH}$ ótimo e de temperatura ótima para ambas lipases imobilizadas. Foi ainda detectada uma mudança na afinidade da enzima imobilizada pelo substrato. Enquanto o $K_{m}$ da enzima livre foi de $170 \mu \mathrm{M}$, as lipases imobilizadas apresentaram os seguintes valores de $K_{m}: 409 \mu \mathrm{M}$, para a enzima imobilizada por adsorção e $210 \mu \mathrm{M}$, para a imobilizada por ligação covalente. Os resultados também mostram que dentre as técnicas testadas para imobilização de lipase de C. rugosa, o sistema imobilizado obtido por ligação covalente foi o mais estável tanto em condições de estocagem como em condições operacionais.

\section{MATERIAL SUPLEMENTAR}

Está disponível em http://quimicanova.sbq.org.br, em forma de arquivo PDF, com acesso livre.

\section{AGRADECIMENTOS}

Ao apoio financeiro concedido pela FAPESP e CAPES.

\section{REFERÊNCIAS}

1. Sharma, R.; Chisti, Y.; Banerjee, U. C.; Biotechnol. Adv. 2001, 19, 627.

2. Houde, A.; Kademi, A.; Leblanc, D. ; Appl. Biochem. Biotechnol. 2004, 155/170, 118

3. Lima, A. W. O.; Agnes, L.; Quim. Nova 1999, 22, 229.

4. Fariha, H.; Aamer, A. S.; Abdul, H.; Enzyme Microb. Technol. 2006, 39, 235.

5. Katchalski-Katzir, E.; Kraemer, D. M.; J. Mol. Catal. B: Enzym. 2000, 10, 157.

6. Zanin, G. M.; Moraes, F. F. Em Enzimas como Agentes Biotecnológicos; Saiad, S.; Pietro, R. C. L. R., eds.; Legis Summa: Ribeirão Preto, 2004, Cap. 4, p. 35-85.

7. Tischer, W.; Kasche, V.; Trends Biotechnol. 1999, 17, 326.

8. Chiou, S. H.; Wu, W. T.; Biomaterials 2004, 25, 197.

9. Jose, N. M.; Prado, L. A. S. de A.; Quim. Nova 2005, 28, 281.

10. Gill, I.; Ballesteros, A.; J. Am. Chem. Soc. 1998, 120, 8587.

11. Soares, C. M. F.; Santos, O. A.; de Castro, H. F.; de Moraes, F. F.; Zanin, G. M.; Appl. Biochem. Biotechmol. 2004, 113-116, 307.

12. Reetz, M. T.; Zonta, A.; Simpelkamp, J.; Rufinska, A.; Tesche, B.; J. SolGel Sci. Technol. 1996, 7, 35.

13. Reetz, M. T.; Zonta, A.; Vijayakrishnan, V.; Schimossek, K.; J. Mol. Catal. A: Chem. 1998, 134, 251.

14. Bruno, L. M.; Lima Filho, J. L.; Melo, E. H. M.; de Castro, H. F.; Appl. Biochem. Biotechnol. 2004, 113/117, 189.

15. Bruno, L. M.; Coelho, J. S.; Melo, E. H. M.; Lima-Filho, J. L.; World J. Microb. Biotechnol. 2005, 21, 189.

16. Paula, A. V.; Barboza, J. C. S.; de Castro, H. F.; Quim. Nova 2005, 28, 792.

17. Paula, A. V.; Urioste, D.; Santos, C. J.; de Castro, H. F.; J. Chem. Technol. Biotechnol. 2007, 85, 281

18. Freitas, L.; Perez, V. H.; Santos, J. C. ; de Castro, H. F.; J. Braz. Chem. Soc., no prelo

19. Gomes, F. M.; Paula, A. V.; Silva, G. S.; de Castro, H. F.; Quim Nova 2006, 29, 710 .

20. Pencreac'h, G.; Baratti, J. C.; Enzyme Microb. Technol. 1996, 18, 417.

21. Fadiloglu, S.; Soylemez, Z.; J. Agric. Food Chem. 1998, 8, 3411.

22. Perez, V. H.; Silva, G. S.; Gomes, F. M.; de Castro, H. F.; Biochem. Eng. J. 2007, 34, 13

23. Montero, S.; Blanco, A.; Virto, M. D.; Landeta, L. C.; Agud, I.; Solozabal, R.; Lascaray, J. M.; Derenobales, M.; Llama, M. J.; Serra, J. L.; Enzyme Microb. Technol. 1993, 15, 239.

24. Reis, P.; Holmberg, K.; Debeche, T.; Folmer, B.; Fauconnot, L.; Watzke, H.; Langmuir 2006, 22, 8169.

25. Stuart, B.; George, W. O.; Mcintyre, P. S.; Modern Infrared Spectroscopy, John Wiley \& Sons, Inc.: Chichester, 1996.

26. Geng, L.; Li, N.; Xiang, M.; Wen, X.; Xu, D.; Zhao, F.; Li, K.; Colloids Surf., $B$ 2003, 30, 99. 
COMPARAÇÃO DO DESEMPENHO DA LIPASE DE Candida rugosa IMOBILIZADA EM SUPORTE HÍBRIDO DE POLISSILOXANO-POLIVINILÁLCOOL EMPREGANDO DIFERENTES METODOLOGIAS

Ariela V. de Paula, Ana B. R. Moreira, Luciana P. Braga e Heizir F. de Castro*

Escola de Engenharia de Lorena, Universidade de São Paulo, CP 116, 12602-810 Lorena - SP, Brasil

Laura M. Bruno

Embrapa Agroindústria Tropical, Rua Dra. Sara Mesquita, 2270, 60511-110 Fortaleza - CE, Brasil

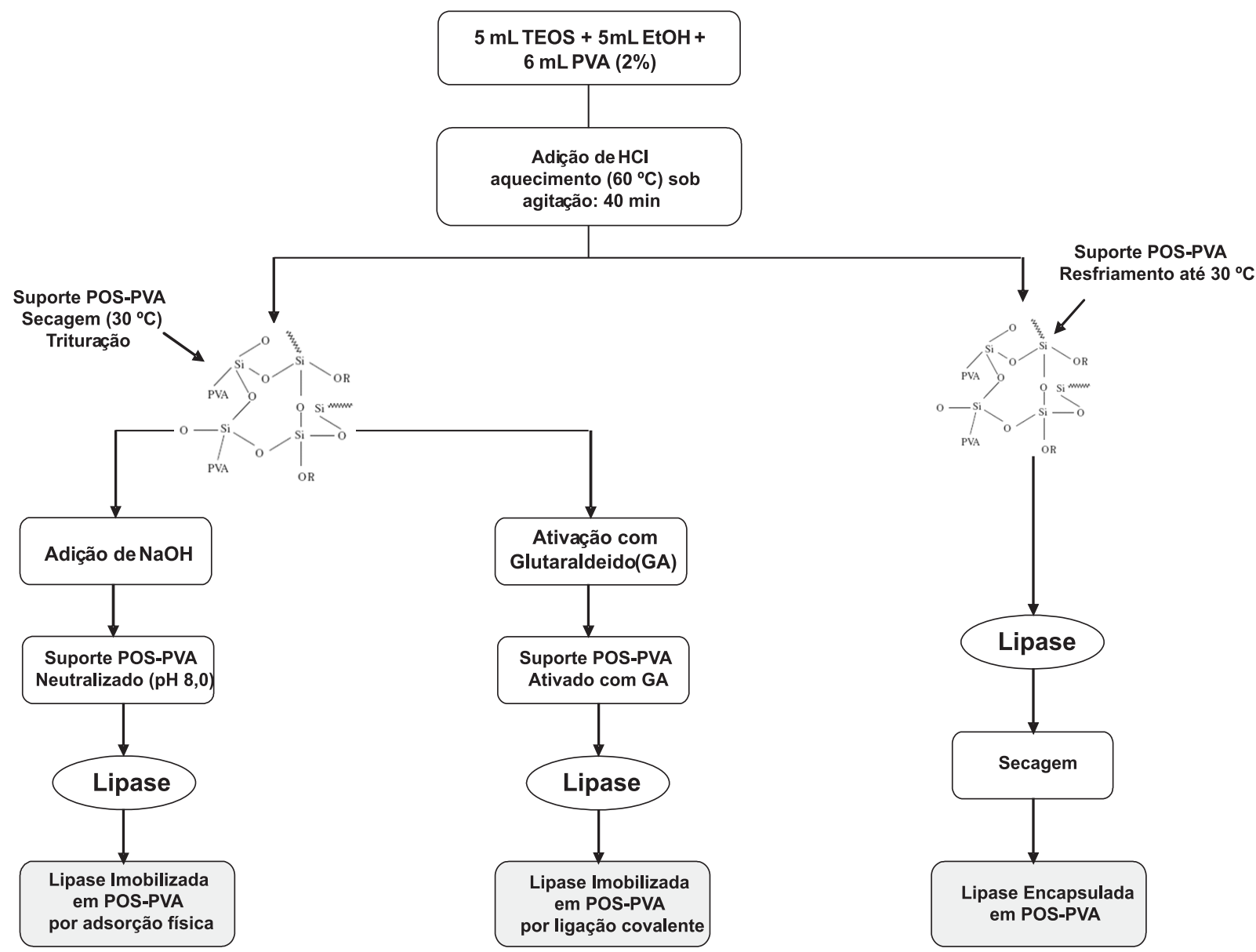

Esquema 1S. Esquema de preparo dos biocatalisadores imobilizados em POS- PVA empregando diferentes técnicas (adsorção física, ligação covalente e encapsulação) 